REGEIVED

HAY O 61999

QSTI

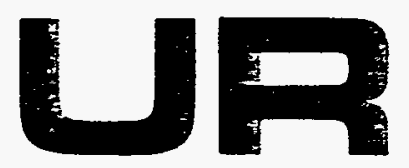

DOE/SF/19460--299-Pt.I
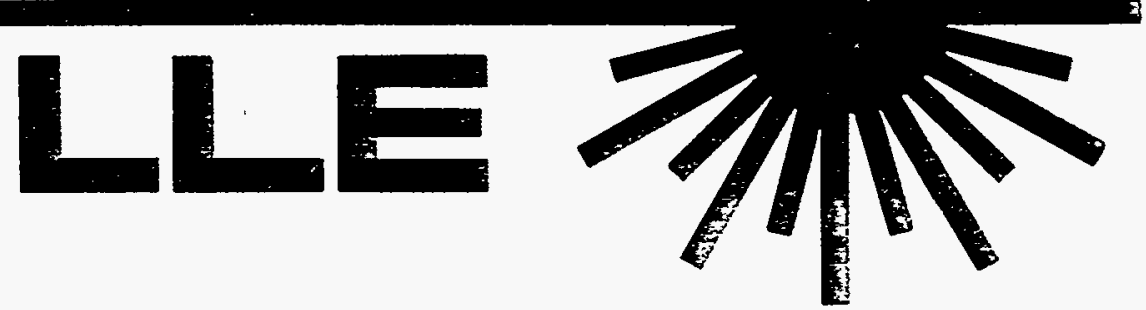

1998 SUMMER RESEARCH PROGRAM FOR HIGH SCHOOL JUNIORS

AT THE

UNIVERSITY OF ROCHESTER'S

LABORATORY FOR LASER ENERGETICS

STUDENT RESEARCH REPORTS

PROJECT COORDINATOR

Dr. R. Stephen Craxton

March 1999

Laboratory Report 300

DISTRIBUTION OF THS DOCUMENT IS UAMMATED

MASTER

Laboratory for Easer Energetics

University of Rochester 


\section{DISCLAIMER}

This report was prepared as an account of work sponsored by an agency of the United States Government. Neither the United States Government nor any agency thereof, nor any of their employees, makes any warranty, express or implied, or assumes any legal liability or responsibility for the accuracy, completeness, or usefulness of any information, apparatus, product, or process disclosed, or represents that its use would not infringe privately owned rights. Reference herein to any specific commercial product, process, or service by trade name, trademark, manufacturer, or otherwise does not necessarily constitute or imply its endorsement, recommendation, or favoring by the United States Government or any agency thereof. The views and opinions of authors expressed herein do not necessarily state or reflect those of the United States Government or any agency thereof. 


\section{DISCLAIMER}

Portions of this document may be illegible in electronic image products. Images are produced from the best available original document. 
1998 SUMMER RESEARCH PROGRAM FOR HIGH SCHOOL JUNIORS

AT THE

UNIVERSITY OF ROCHESTER'S

LABORATORY FOR LASER ENERGETICS

\title{
STUDENT RESEARCH REPORTS
}

\section{PROGRAM COORDINATOR}

\author{
Dr. R. Stephen Craxton \\ LABORATORY FOR LASER ENERGETICS \\ University of Rochester \\ 250 East River Road \\ Rochester, NY 14623-1299
}

During the summer of 1998, 11 students from Rochester-area high schools participated in the Laboratory for Laser Energetics' Summer High School Research Program. The goal of this program is to excite a group of high school students about careers in the areas of science and technology by exposing them to research in a state-ofthe-art environment. Too often, students are exposed to "research" only through classroom laboratories that have prescribed procedures and predictable results. In LLE's summer program, the students experience all of the trials, tribulations, and rewards of scientific research. By participating in research in a real environment, the students often 
become more excited about careers in science and technology. In addition, LLE gains from the contributions of the many highly talented students who are attracted to the program.

The students spent most of their time working on their individual research projects with members of LLE's technical staff. The projects were related to current research activities at LLE and covered a broad range of areas of interest including optics, spectroscopy, chemistry, diagnostic development, and materials science. The students, their high schools, their LLE supervisors and their project titles are listed in the table. Their written reports are collected in this volume.

The students attended weekly seminars on technical topics associated with LLE's research. Topics this year included lasers, fusion, holography, nonlinear optics, global warming, and scientific ethics. The students also received safety training, learned how to give scientific presentations, and were introduced to LLE's resources, especially the computational facilities.

The program culminated with the High School Student Summer Research Symposium on 26 August at which the students presented the results of their research to an audience that included parents, teachers, and members of LLE. Each student spoke for approximately ten minutes and answered questions. At the symposium an Inspirational Science Teacher award was presented to Mr. David Crane, a chemistry teacher at Greece Arcadia High School. This annual award honors a teacher, nominated by alumni of the LLE program. who has inspired outstanding students in the areas of science, mathematics, and technology. 


\begin{tabular}{|c|c|c|c|}
\hline \multicolumn{4}{|c|}{ High School Students and Their Projects (1998) } \\
\hline Student & High School & Supervisor & Project \\
\hline Steven Corsello & Pittsford Mendon & K. Marshall & $\begin{array}{l}\text { Computer-Aided Design and } \\
\text { Modeling of Nickel Dithiolene } \\
\text { Near-Infrared Dyes }\end{array}$ \\
\hline Peter Grossman & Wilson Magnet & R. S. Craxton & $\begin{array}{l}\text { Group Velocity Effects in } \\
\text { Broadband Frequency } \\
\text { Conversion on OMEGA } \\
\end{array}$ \\
\hline Joshua Hubregsen & Pittsford Sutherland & S. Jacobs & \begin{tabular}{|l} 
A Study of Material Removal \\
During Magnetorheological \\
Finishing (MRF) \\
\end{tabular} \\
\hline Nieraj Jain & Pittsford Sutherland & M. Guardelben & \begin{tabular}{|l} 
Analyzing Algorithms for \\
Nonlinear and Spatially \\
Nonuniform Phase Shifts in \\
the Liquid Crystal Point \\
Diffraction Interferometer \\
\end{tabular} \\
\hline Leslie Lai & Pittsford Mendon & M. Wittman & $\begin{array}{l}\text { The Use of Design-of- } \\
\text { Experiments Methodology to } \\
\text { Optimize Polymer Capsule } \\
\text { Fabrication }\end{array}$ \\
\hline Irene Lippa & Byron-Bergen & K. Marshall & \begin{tabular}{|l} 
Synthesis and Analysis of \\
Nickel Dithiolene Dyes in a \\
Nematic Liquid Crystal Host \\
\end{tabular} \\
\hline $\begin{array}{l}\text { Phillip } \\
\text { Ostromogolsky }\end{array}$ & Brighton & F. Marshall & \begin{tabular}{|l|} 
Investigation of the X-Ray \\
Diffraction Properties of a \\
Synthetic Multilayer \\
\end{tabular} \\
\hline $\begin{array}{l}\text { Michael } \\
\text { Schubmehl }\end{array}$ & The Harley School & R. Epstein & $\begin{array}{l}\text { An Analysis of the Uncertainty } \\
\text { in Temperature and Density } \\
\text { Estimates from Fitting Model } \\
\text { Spectra to Data }\end{array}$ \\
\hline Joshua Silbermann & Penfield & P. Jannimagi & $\begin{array}{l}\text { Automated CCD Camera } \\
\text { Characterization }\end{array}$ \\
\hline Abigail Stern & The Harley School & J. Knauer & \begin{tabular}{|} 
Design and Testing of a \\
Compact X-Ray Diode \\
\end{tabular} \\
\hline Amy Turner & Churchville-Chili & R. S. Craxton & $\begin{array}{l}\text { Ray Tracing Through the Liquid } \\
\text { Crystal Point Diffraction } \\
\text { Interferometer }\end{array}$ \\
\hline
\end{tabular}


A total of 91 high school students have participated in the program since it began in 1989. The students this year were selected from approximately 60 applicants. Each applicant submitted an essay describing their interests in science, a copy of their transcript, and a letter of recommendation from a science or math teacher.

LLE plans to continue this program in future years. The program is strictly for students from Rochester-area high schools who have just completed their junior year. Applications are generally mailed out in February with an application deadline near the end of March. For more information about the program or an application form, please contact Dr. R. Stephen Craxton at LLE.

This program was supported by the U.S. Department of Energy Office of Inertial Confinement Fusion under Cooperative Agreement No. DE-FC03-92SF19460. 
COMPUTER-AIDED DESIGN AND MODELING OF NICKEL DITHIOLENE NEAR-INFRARED DYES

by

\section{STEVEN CORSELLO}

Pittsford Mendon High School

Pittsford, NY 


\title{
Computer-Aided Design and Modeling of \\ Nickel Dithiolene Near-Infrared Dyes
}

\author{
Steven Corsello \\ Advisor: Kenneth L. Marshall \\ Laboratory for Laser Energetics \\ University of Rochester \\ Summer High School Research Program \\ 1998
}

\begin{abstract}
Recent advances in computational chemistry have made it feasible to design many types of molecules and predict their properties theoretically. I applied these techniques to the design of organometallic transition-metal dyes absorbing in the near-infrared region of the spectrum which possess the combination of a large molar extinction coefficient, good chemical and thermal stability, and a high solubility in liquid crystal (LC) hosts. These properties are required for the dye to function as a near-infrared (IR) attenuator in a liquid crystal point diffraction interferometer (LCPDI) device that will be used as a beam diagnostic on the 60-beam OMEGA solid-state Nd:glass laser system at the University of Rochester's Laboratory for Laser Energetics. Using commercially available software, both the absorption spectra and solubility characteristics of bis[1,2-di-(p-n alkoxyphenyl) ethane-1,2-dithione) nickel dye complexes were modeled in an isotropic host (cyclohexane) and, in most cases, excellent agreement was found with experimental data. Two additional compounds utilizing the same nickel dithiolene core but with alkylthio and phenylalkylthio terminal groups have been designed and show excellent potential to produce dramatic improvements in both solubility and optical density (absorbance) in liquid crystalline hosts. Based upon my work, a new dye not previously reported, $2\left(\mathrm{C}_{4} \mathrm{~S}\right) 2\left(\mathrm{C}_{4} \mathrm{SPh}\right) \mathrm{DTNi}$, has been proposed to satisfy the LCPDI device requirements. The nickel dithiolene dyes may also find important applications in other technology areas such as near-IR photography and laser-based near-IR communications.
\end{abstract}




\section{1) Introduction}

As the dawn of the twenty-first century approaches, nuclear fusion holds increasing promise as a viable and inexhaustible energy source. Scientists at the University of Rochester's Laboratory for Laser Energetics are studying the physics of inertial confinement fusion (ICF) via "direct drive" irradiation using the world's most powerful ultraviolet laser: the 40 terawatt, 60-beam OMEGA Nd:glass solid-state laser system. Under direct drive ICF, sixty UV (351 nm) laser beams, formed by frequency conversion of the 1054-nm laser to the third harmonic, converge upon a small fuel pellet containing the hydrogen isotopes deuterium and tritium. ${ }^{1}$ The laser serves to ionize the target's outer layer, and the plasma generated then ablates from the pellet at a high velocity. According to Newton's third law, an equal and opposite force is directed inward. This force accelerates the rest of the pellet inward in the time frame of a few nanoseconds. The compression creates extremely high temperature and pressure, allowing the isotopes of hydrogen to fuse.

Although considerable progress towards achieving the goals of ICF has been made in recent years, much work still remains in improving direct drive laser systems to the point at which fusion can be used as an energy source. Because of difficulties in manufacturing the very large optical elements used in the OMEGA system, these optics can add aberrations to each laser beam that can result in wavefront errors in the incident beams. Such wavefront errors can manifest themselves in non-uniform illumination of the target.

Although numerous diagnostic instruments are used on OMEGA in order to analyze beam uniformity problems, a more effective method of measuring wavefront aberrations is required. The present method, which employs traditional interferometry to analyze OMEGA beam lines, is limited in that it (1) can only perform gradient measurements in two directions; (2) has low sensitivity to high order phase errors; and (3) has low spatial resolution. These difficulties can be overcome using a new type of interferometer device that relies on an electro-optical liquid crystal (LC) cell as the primary modulation element. This liquid crystal point diffraction interferometer 
$(\mathrm{LCPDI})^{2}$, shown in Figure 1, offers several important advantages in that it is extremely compact, does not suffer from the limitations described above for other interferometers, and has the ability to measure wavefront quality directly.

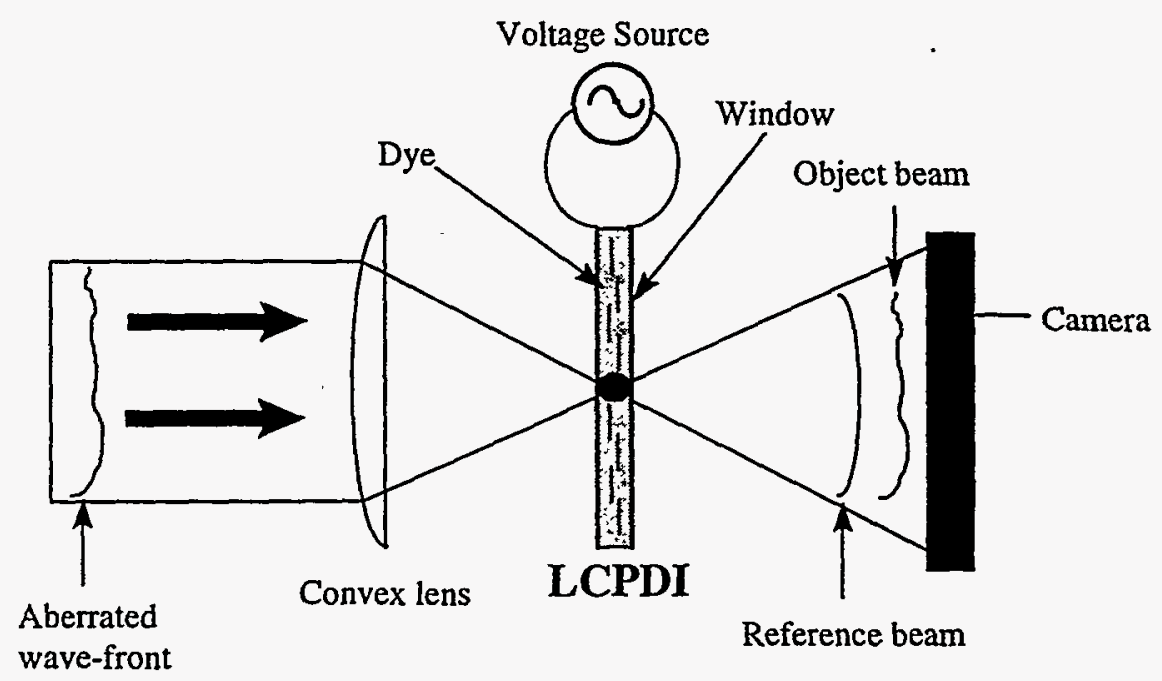

Fig. 1: The liquid crystal point diffraction interferometer (LCPDI) allows aberrations to be seen by interfering the front with a reference beam.

The LCPDI device incorporates a single glass microsphere embedded in the LC fluid layer that acts as the reference portion of the interferometer. The liquid crystal can be oriented by applying a voltage to the LCPDI, allowing the LC fluid's refractive index to be changed. The incident beam is focused on the area of the cell that contains the microsphere, and optical interference occurs between the small portion of the beam that passes through the glass microsphere and the rest of the beam which passes through the LC fluid. The small portion of the beam which passes through the microsphere is refracted to form the reference beam. Because the reference beam is formed from a very small portion of the incident light, it is necessary to attenuate the strength of the object beam using the dye. This allows sufficient contrast to be seen between the reference and object beams and thus allows the output images to be analyzed. The dye used in the device must meet a number of important criteria:

- A strong absorption maximum at or near the wavelength of incident laser radiation (in this case $1054 \mathrm{~nm}$, since the device will be deployed in the laser system at a point before the frequency conversion to ultraviolet light takes place) 
- High solubility in the LC host to maximize contrast and avoid long-term precipitation

- Excellent chemical and thermal stability

- Low impact on the mesophase order of the LC host

Although there are a number of commercially-available laser dyes that absorb in the near-infrared region, most of these are soluble only in polar solvents such as methanol, acetone, or dichloromethane and thus show poor solubility in hydrocarbon-like LC hosts. ${ }^{3}$ This lack of a suitable commercial dye satisfying both the solubility and absorption requirements necessitates the development of a new dye or series of dyes which would enable the LCPDI device to meet these specific design goals.

The traditional approach to the development of new materials, which involves synthesis of a homologous series of target compounds and empirical determination of their physical properties, is well-know to be a very costly, time-consuming, and laborintensive process. Spurred on largely by both the needs of the pharmaceutical industry to drastically reduce the development time for bringing new products to market and advances in computational methods and hardware, chemists have increasingly turned to the predictive capabilities of computational chemistry and molecular modeling to target for synthesis only those compounds that are the most promising.

My work utilized several commercial software packages to predict both the solubility and the spectral absorption maxima of candidate dye molecules in suitable host systems. The computational methods were first tested using common solutes. In most cases, I was able to achieve excellent agreement with experimental results, encountering software limitations. Cyclohexane was chosen as a non-polar solvent to mimic the use of liquid crystal. After the accuracy of these computational methods was proven, they were then applied to the design of new dyes, utilizing unique functional groups.

The dye systems that were chosen for study are based on zerovalent transition metal dithiolene complexes, which are known both to exhibit strong absorption bands in the $600-1500 \mathrm{~nm}$ region of the spectrum ${ }^{4}$ and to be soluble in non-polar organic solvents, 
depending on the dye's molecular structure. My investigations focused on compounds using nickel as the central transition element (Fig. 2)
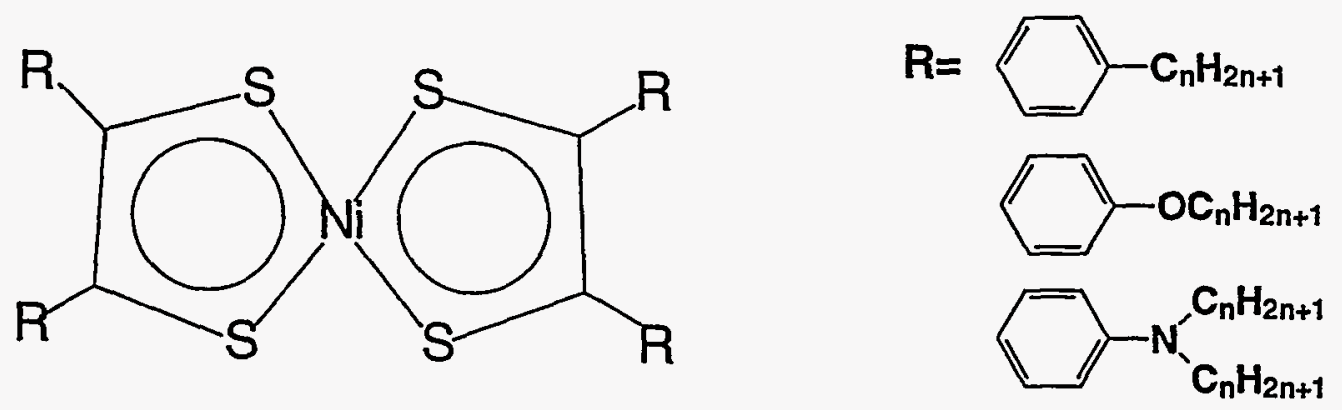

Fig. 2: The molecular structure of transition metal nickel dithiolenes. Compounds containing the functional groups shown to the right were evaluated both theoretically and experimentally.

Nickel dithiolenes are of special interest for this application both because of their high solubility in liquid crystalline hosts of certain analogs and because the dyes themselves can possess liquid crystalline properties if appropriate functional groups are selected. ${ }^{5}$ The latter is a distinct advantage, in that it would allow higher concentrations of the dye to be added to the liquid crystalline host without substantially reducing the degree of order of the host mesophase. Thus, the new dyes were designed around the nickel dithiolene core structure in order to create a near- $\mathbb{R}$ dye that will be soluble in liquid crystal. This would fulfill the design requirements of the LCPDI device and also allow for the use of the dye in fields where liquid crystals are being investigated for their unique properties. One such property is their ability to act as light polarizers, thus showing potential for use in near-IR laser communication systems. Also, the dyes' strong near- $\mathbb{R}$ absorption may be useful for near-IR photography.

\section{2) Structural Modeling}

Structural energy minimization calculations were undertaken prior to both electronic spectra and solubility calculations using Spartan 5.0 (Wavefunction, Inc.) to insure that the structural geometry of the compounds under evaluation was in its lowest energy conformation. The Spartan package runs on a Digital AlphaServer under DEC UNIX and supports all four major methods of geometry optimization ${ }^{6}$ : ab initio Hartree- 
Fock, $a b$ initio correlated, density functional and semi-empirical. Semi-empirical methods were chosen for these calculations for the following reasons: (1) Ab initio methods, although very accurate, are also extremely computationally intensive for anything but very small molecules; (2) density functional methods are also computationally intensive and have difficulty in handling transition metals; and (3) semi-empirical methods can accurately predict equilibrium geometry using much less computing resources and, when proper parameters for transition metals are applied, can accurately take into account contributions from bonding to $d$-orbitals.

The PM3 semi-empirical model is a reparamaterization of the original AM1 model. ${ }^{7}$ These models are based upon the neglect of diatomic differential overlap (NDDO) approximation. The geometry optimization calculations employed the PM3 parameter set for transition metals. When compared to $\mathrm{x}$-ray diffraction data from the literature $^{8}$ for the compound bis[(octyl-4 phenyl)-1 ethylenedithiolato-1,2]nickel (Figure 3 ), this method produced quite accurate results as shown by the agreement between calculated and experimental bond lengths (Table 1).

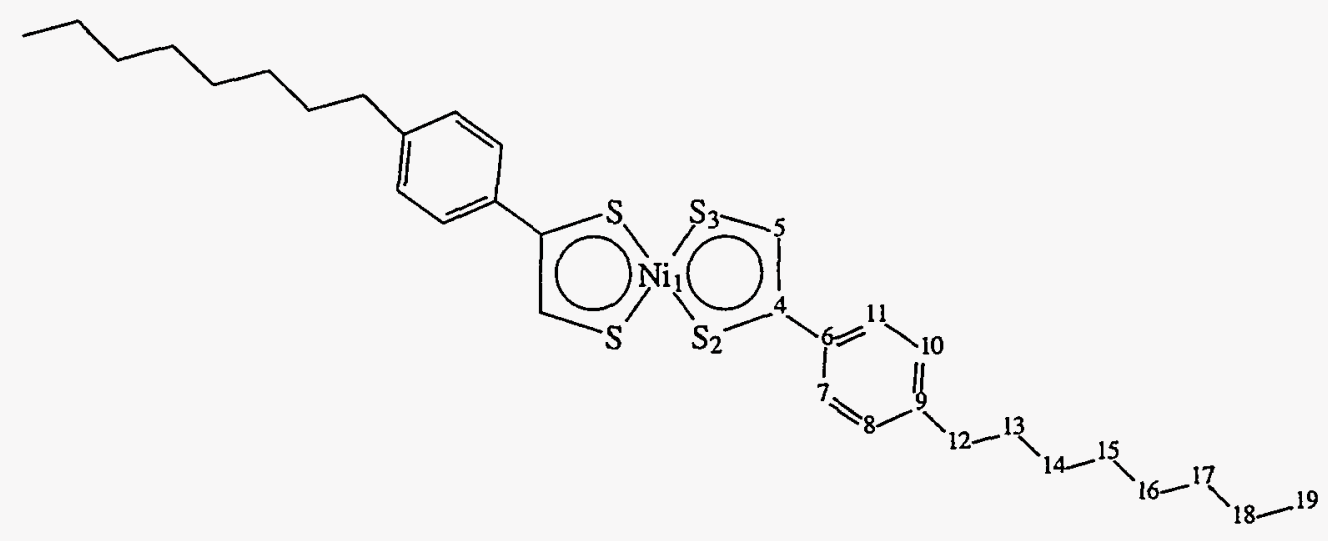

Figure 3: The structure of bis[(octyl-4 phenyl)-1 ethylenedithiolato-1,2]nickel. The bond lengths shown in Table 1 correspond with the numbered elements above. 


\begin{tabular}{|c|c|c|c|}
\hline Bond & $\begin{array}{c}\text { Experimental } \\
\text { bond length }(\AA)\end{array}$ & $\begin{array}{c}\text { Calculated } \\
\text { bond length }(\AA)\end{array}$ & Percent Error \\
\hline $\mathrm{Ni}(1)-\mathrm{S}(2)$ & 2.130 & 2.1649 & 1.6385 \\
\hline $\mathrm{Ni}(1)-\mathrm{S}(3)$ & 2.116 & 2.1611 & 2.1314 \\
\hline$S(2)-C(4)$ & 1.705 & 1.7139 & 0.5220 \\
\hline$S(3)-C(5)$ & 1.680 & 1.6818 & 0.1071 \\
\hline$C(4)-C(5)$ & 1.383 & 1.3796 & 0.2458 \\
\hline$C(4)-C(6)$ & 1.478 & 1.4627 & 1.0352 \\
\hline$C(6)-C(7)$ & 1.395 & 1.3987 & 0.2652 \\
\hline$C(7)-C(8)$ & 1.379 & 1.3885 & 0.6889 \\
\hline$C(8)-C(9)$ & 1.374 & 1.3961 & 1.6084 \\
\hline$C(9)-C(10)$ & 1.383 & 1.3956 & 0.9111 \\
\hline$C(10)-C(11)$ & 1.377 & 1.3889 & 0.8642 \\
\hline$C(11)-C(6)$ & 1.376 & 1.3985 & 1.6352 \\
\hline$C(12)-C(9)$ & 1.513 & 1.4943 & 1.2360 \\
\hline$C(12)-C(13)$ & 1.513 & 1.5231 & 0.6675 \\
\hline$C(13)-C(14)$ & 1.522 & 1.5202 & 0.1183 \\
\hline$C(14)-C(15)$ & 1.510 & 1.5203 & 0.6821 \\
\hline$C(15)-C(16)$ & 1.506 & 1.5204 & 0.9562 \\
\hline$C(16)-C(17)$ & 1.522 & 1.5202 & 0.1183 \\
\hline$C(17)-C(18)$ & 1.509 & 1.5206 & 0.7687 \\
\hline$C(18)-C(19)$ & 1.511 & 1.5122 & 0.0794 \\
\hline
\end{tabular}

Table 1: Comparison of calculated and experimental ${ }^{8}$ values for bond lengths in bis[(octyl-4 phenyl)-1 ethylenedithiolato-1,2]nickel. The molecular structure is shown in Fig. 3.

\section{3) Solvation}

The solubility of a given solute in a solvent can be approximated by calculating its solvation energy and comparing this value with the bonding, or "reorganization" energy. The solvation energy, $\Delta G_{\text {solv }}$ is defined as: ${ }^{9}$

$$
\Delta G_{\text {solv }}=\Delta G_{\text {elec }}+\Delta G_{c o v}+\Delta G_{\text {disp }}+\Delta G_{v i b}+\Delta G_{l i b}+\Delta G_{\text {other }}
$$

where:

$\Delta G_{\text {elec }}=$ electrostatic solute - solvent interaction

$\Delta G_{c o v}=$ energy to form solute shaped cavity

$\Delta G_{\text {disp }}=$ London and van der Waals interactions

$\Delta G_{v i b}=$ change in vibrational energy due to damping

$\Delta G$ lib $=$ conversion of rotations and translations to librations

$\Delta G_{\text {other }}=$ solvent enthalpic and entropic structure (PV term, etc.) 
Although Spartan 5.0 has the ability to conduct geometry optimization in solution, it is not capable of dealing with $d$-orbitals in the solvation calculations. ${ }^{10}$ Because the metal $d$-orbitals play an extremely important role in determining the properties of the nickel dithiolenes, they must be taken into account in these calculations in order to obtain valid results. Jaguar 3.5 (Schrödinger, Inc.), another UNIX-based package, does have this capability. Using the dielectric constant, molecular weight, and density of the solvent, Jaguar determines a probe radius that is used for the calculation of the solvation energy. ${ }^{11}$

Solvated molecular systems are treated by Jaguar by means of a self-consistent reaction field method using its own Poisson-Boltzmann solver. The Poisson-Boltzmann equation is defined as: ${ }^{12}$

$$
\begin{gathered}
\nabla \cdot \varepsilon(r) \nabla \phi(r)-\varepsilon K^{2} \sinh [\phi(r)]+4 \pi q \rho^{f}(r) / k T=0 \\
\text { where } \\
K^{2}=\frac{1}{\lambda^{2}}=\frac{8 \pi q^{2} I}{\varepsilon k T} \\
\lambda=\text { Debye length } \\
I=\text { ionic strength of the bulk solution } \\
\phi(\mathrm{r})=\text { dimensionless electrostatic potential } \\
\mathrm{k}=\text { Boltzmann constant } \\
\mathrm{T}=\text { absolute temperature } \\
\mathrm{q}=\text { proton charge } \\
\rho^{\mathrm{f}}=\text { fixed charge density } \\
\varepsilon=\text { dielectric constant }
\end{gathered}
$$

The Poisson-Boltzmann equation allows the program to solve for the elements of the solvation energy according to the three-dimensional grid mapped out through the use of the finite difference method. Before using Jaguar to calculate the solubilities of the nickel dithiolene dyes, the accuracy of the software was first tested by calculating the solubilities of several common solutes (water, methanol, n-propanol, benzene, and methylcyclohexane) in a hydrocarbon-like solvent that would somewhat approximate the nature of the LC host. The LC host material (E7, Merck Ltd) used in the LCPDI device is a commercial room-temperature eutectic mixture of alkyl and alkoxy cyanobiphenyl and cyanoterphenyl compounds commonly used in the construction of LC devices (Fig. 4). 


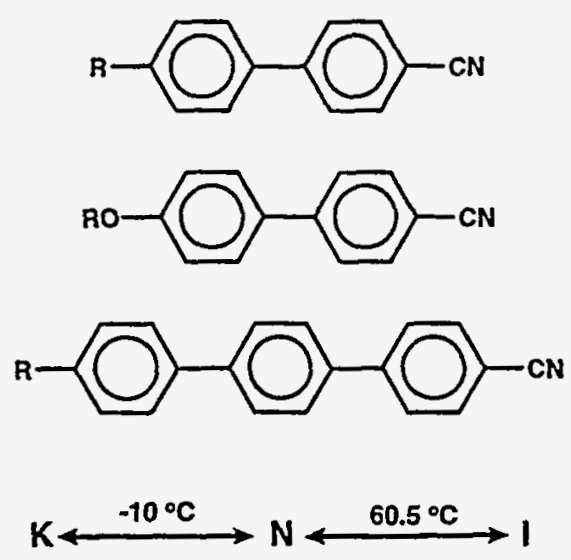

Fig. 4: Components of the commercial LC eutectic mixture E7 (Merck, Ltd). The substituents designated as " $R$ " in the structures are alkyl groups of various lengths.

Cyclohexane was chosen as the solvent for these initial calculations due to its non-polar, hydrocarbon nature which helped to approximate solubility in the eutectic E7 LC mixture. The results obtained are shown below in Fig. 5. These values agreed very well with experimentally observed trends, and provided us the confidence to proceed with dye solubility calculations.

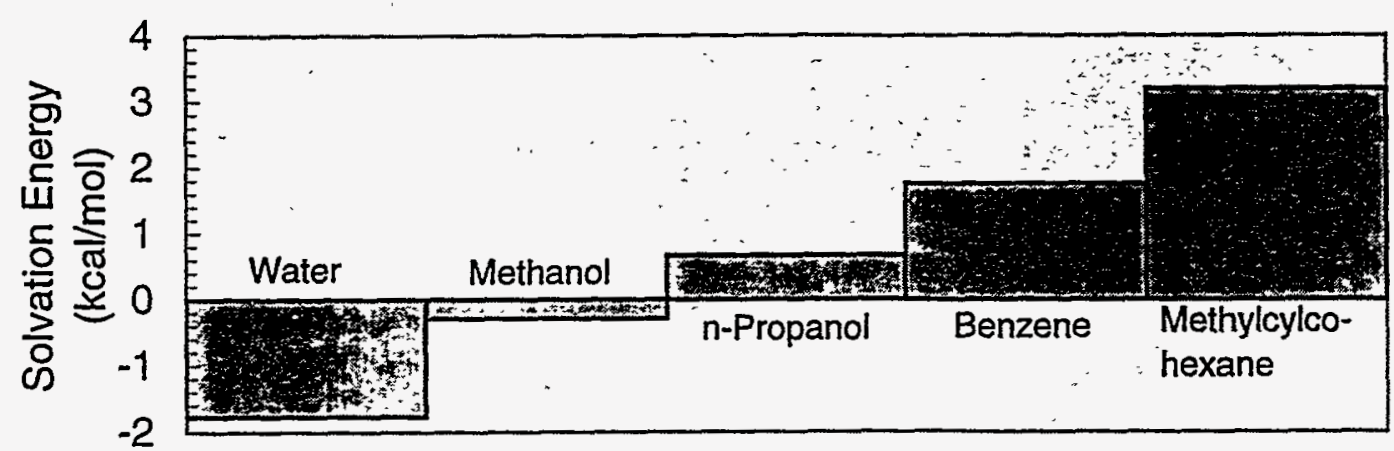

Fig. 5: Solvation energies of common solutes in cyclohexane.

Ideally, the next step would be to utilize the LC host mixture E7 as the solvent and proceed with the solubility calculations for the dyes; however, this was not feasible because the software is unable to handle either a mixture of solvents or individual solvent materials that are anisotropic in their physical properties as are LC materials. The next strategy was to attempt to use a single cyanobiphenyl compound as the solvent and treat the material as isotropic by using average values of the anisotropic physical properties. Attempts at conducting solvation energy calculations using 4-cyano-4'-n-pentylbiphenyl as the solvent failed due to a limitation of Jaguar in handling solvents that have a probe 
radius greater than $3.1^{13}$. Attempts at repeating the calculation using 4-n-butylbenzene, which is substantially shorter and possessed a probe radius only slightly larger than the maximum value (Table 2), also failed.

\begin{tabular}{|c|c|c|c|c|}
\hline Solvent host & $\begin{array}{c}\text { Dielectric } \\
\text { constant }\end{array}$ & $\begin{array}{c}\text { Molecular } \\
\text { weight } \\
\text { (g/ mol) }\end{array}$ & $\begin{array}{c}\text { Density } \\
(g / c c)\end{array}$ & $\begin{array}{c}\text { Probe } \\
\text { radius } \\
(\AA)\end{array}$ \\
\hline Cyclohexane $^{17}$ & 2.02 & 84.16 & 0.779 & 2.777 \\
\hline $\begin{array}{l}\text { 4-Cyano-4'-n-pentyl } \\
\text { biphenyl }\end{array}$ & 11.50 & 249.35 & 1.019 & 3.647 \\
\hline n-Butylbenzene ${ }^{16,17}$ & 2.41 & 134.22 & 0.860 & 3.139 \\
\hline
\end{tabular}

Table 2: Parameters of various solvents employed in solvation energy calculations

Part of the difficulty was in the fact that the probe radius calculation assumes a rigid spherical solvent, whereas the alkylcyanobiphenyls (and, to a certain extent, nbutylbenzene) are long, cigar-shaped molecules. Because of these limitations, we chose to conduct a less rigorous calculation using cyclohexane as the solvent to obtain at least a qualitative picture of the solubility trends of the nickel dithiolenes in a hydrocarbon-like host.

Solvation energy calculations were conducted on four nickel dithiolene compounds containing either alkyl, alkoxy, or dimethylamino terminal groups. All of the compounds were synthesized in our laboratory with the exception of the dimethylamino compound, which was available commercially. Figure 6 compares the calculated and experimentally observed solubilities of the four metal complexes in cyclohexane. Experimental values were determined by preparing solutions of the complexes at several concentrations in cyclohexane and observing the solutions at regular intervals (once daily) for signs of precipitation. The maximum solution concentration of each nickel dithiolene complex that was able to survive for at least two weeks without precipitation was taken to be its solubility limit. It is very difficult to equate the solvation energy values into actual solubility. Thus, the solvation energies are best used to view relative solubilities between dyes. Figure 6 overlays the calculated solvation energies with experimental observations in order to demonstrate relative trends. 


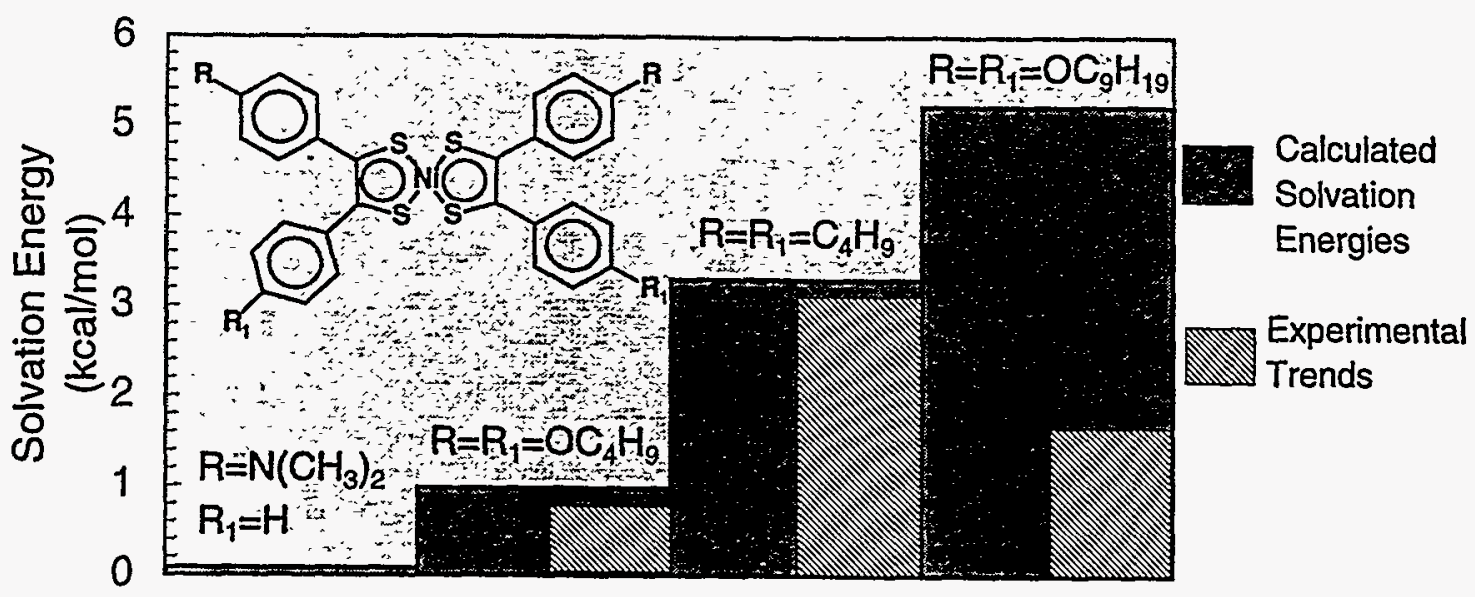

Fig. 6: Approximate comparison of the calculated solvation energies and experimentally observed trends of nickel dithiolenes in cyclohexane.

Excellent agreement was obtained between the calculated and experimental solubilities ${ }^{18}$ of the dimethylamino $\left(\mathrm{R}=\mathrm{N}\left(\mathrm{CH}_{3}\right)_{2}\right)$, butyl, and butoxy derivatives. For the nonyloxy derivative, however, Jaguar reported a value of the solvation energy in cyclohexane that was substantially higher than was found experimentally. Initially, this error was attributed to a computational problem involving poor SCF (self consistent field) convergence, which is known to occur in very large organometallic systems ${ }^{11}$ such as the $\mathrm{OC}_{9} \mathrm{H}_{19}$ dye studied here (165 atoms). However, recent chromatographic and thermoanalytical evidence indicates that the purity of the $\mathrm{OC}_{9} \mathrm{H}_{19}$ material is in question and may be responsible for the lower than expected experimental solubility. This issue is currently under investigation.

\section{4) Dye Absorption}

The strong near-infrared absorption maximum observed in the nickel dithiolenes is a function of both extensive electron delocalization about the dithiolene ring system and interaction of this delocalized system with available d-orbitals on the central metal. ${ }^{19}$ This interaction can be depicted both graphically and mathematically through the linear combination of atomic orbital-molecular orbital(LCAO-MO) theory. The atomic orbitals of the individual atoms are combined to form a series of lower energy "bonding" and higher energy "anti-bonding" molecular orbitals. Absorption of photons of sufficient energy by the molecule results in the promotion of electrons from occupied (bonding) 
molecular orbitals to unoccupied (anti-bonding) molecular orbitals. The lowest energy transition is between the highest occupied molecular orbital (HOMO) and the lowest unoccupied molecular orbital (LUMO). This lowest-energy transition, referred to as the "bandgap", occurs at the longest wavelength and is responsible for the strong near-IR absorption in the nickel dithiolenes ${ }^{20}$. Figure 7 below shows electron density probability maps over the nickel dithiolene core as generated by Spartan 5 . The red areas on the maps represent regions where there is the greatest probability of locating high electron density.

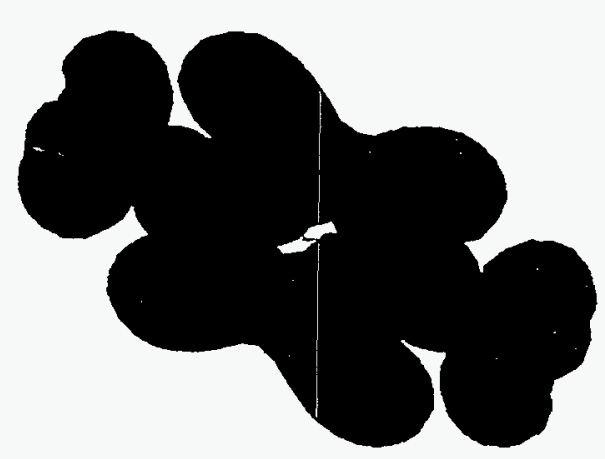

Highest Occupied Molecular Orbital (HOMO)

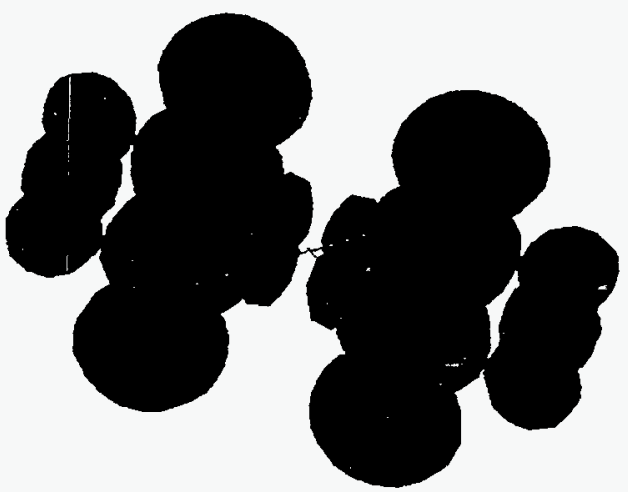

Lowest Unoccupied Molecular Orbital (LUMO)

Fig 7: Electron density probability maps of HOMO (left) and the LUMO (right) for the nickel dithiolene core. The red areas indicate the locations where there is the greatest probability of high electron density.

The energy levels in electron volts for each molecular orbital can also be represented numerically and graphically, as shown below in Fig. 8 for the nickel dithiolene core of Fig. 7. Although Spartan is capable of generating the HOMO-LUMO diagrams, it does not have the capability to calculate full MO diagrams or electronic spectra for systems involving transition metals. ${ }^{11}$ For these calculations, HyperChem 5.1 (Hypercube, Inc), running on a Windows NT Pentium Pro PC workstation, was employed. Computations were accomplished by importing into Hyperchem structures in the Brookhaven protein databank file (PDB) format that had previously been energyminimized by Spartan. 


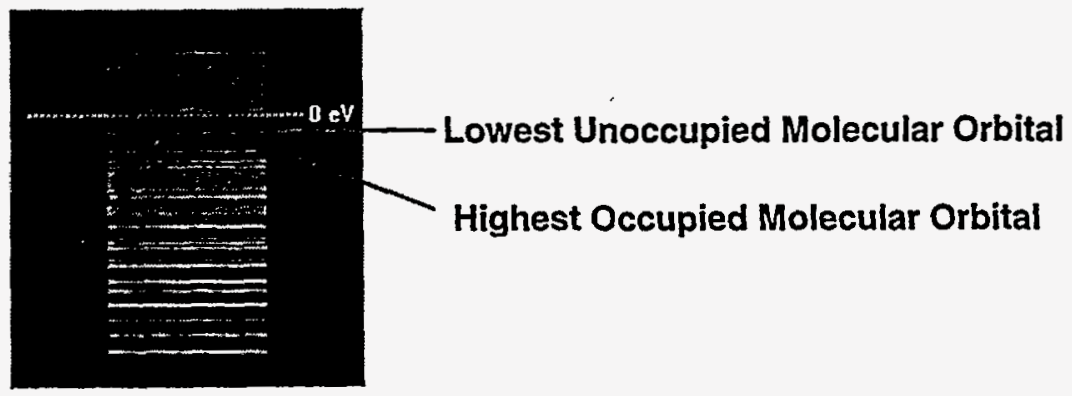

Fig. 8: Energy levels for bonding and antibonding molecular orbitals in the nickel dithiolene core.

After computation of the energy levels for the bonding and antibonding molecular orbitals for nickel dithiolenes with various functional groups attached, this data can be used to calculate the expected absorption maxima for each individual compound and generate a complete electronic spectrum across the UV, visible, and near-IR ranges. Figure 8 shows the results obtained on a trial calculation for a nickel dithiolene bearing two alkylphenyl substituents previously reported in the literature. ${ }^{7}$ The calculation was performed in the gas phase using the ZINDO/S computational method ${ }^{21}$, which was the preferred method for electronic spectra calculations. Hyperchem is limited to conducting these calculations in either the gas phase or in water solution.
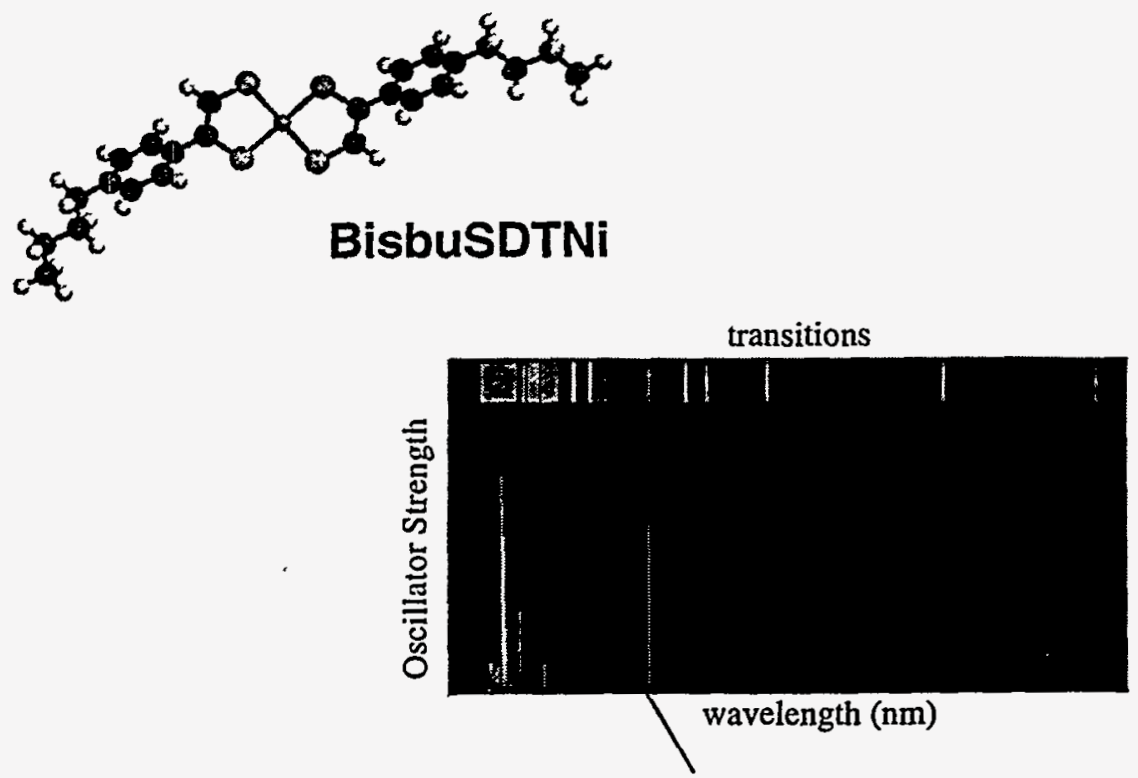

$851.36 \mathrm{~nm}$

Fig. 9: Electronic spectrum calculations obtained on bis(p-n-butylstyryl-1,2-dithiolato)nickel (BisbuSDTNi) in the gas phase using Hyperchem 5.1 (ZNNDO/S) 
The result for the absorption maximum is remarkably close to the actual values for this same compound in both isotropic and liquid crystalline hosts, as can be seen in Fig. 10 below.

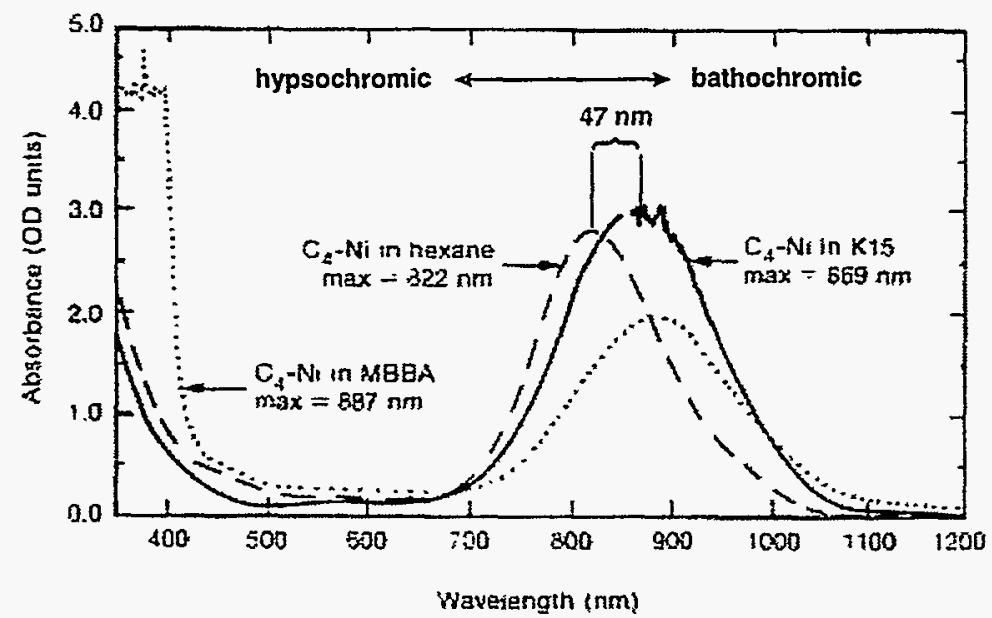

Fig. 10: Absorption spectra for BisbuSDTNi dissolved in hexane and two liquid crystalline hosts. ${ }^{5}$ A bathochromic (IR) shift occurs when the host solvent is changed from hexane to LC.

Although excellent results were obtained with systems containing only two phenyl substituents, errors between calculated and experimental values were encountered for systems with more than two phenyl groups attached to the nickel dithiolene core (e.g., the dimethylamino, alky, and alkoxy-substituted compounds of Fig. 6). These errors may be due to computational difficulties that are a result of the large number of molecular orbitals involved in the calculations. Work is currently underway using both Hyperchem and a second modeling package, Cerius ${ }^{2} 3.5$ (Molecular Simulations, Inc.) to further improve these calculations.

\section{5) Design and Modeling of Highly Soluble Nickel Dithiolenes for the LCPDI}

Optimal performance of the LCPDI device requires the dye component to have both the maximum possible solubility in the host material and the largest possible optical absorbance in the near IR. Using the computational tools and methods developed in the previous sections, different combinations of functional groups were tested on the nickel dithiolene core to observe their effect on both solubility and optical absorption. In the compounds discussed previously, oxygen bridges have typically been used to connect the 
nickel dithiolene core with the terminal hydrocarbon chains. Here the effect of replacing the oxygen bridges with sulfur was examined. Sulfur, unlike oxygen, has available $d$ orbitals that could potentially improve electron delocalization by overlap with orbitals in the nickel dithiolene core. To test this assumption, several alkylthio-substituted compounds were designed and their solvation energies were calculated in cyclohexane. The results of these calculations, shown below in Table 3, indicate that the simple substitution of sulfur for oxygen (in the last two compounds of Table 3) yielded a dramatic improvement in solubility in a cyclohexane host.

\begin{tabular}{|c|c|c|c|}
\hline \multicolumn{4}{|l|}{ Solute } \\
\hline$-R_{1}$ & $\begin{array}{l}\text { Solvation energy } \\
\left(\Delta \mathrm{G}_{\text {solv }}, \mathrm{kcal} / \mathrm{mol}\right)\end{array}$ & $\begin{array}{c}\text { Reorganization } \\
\text { energy } \\
\left(\Delta G_{\text {reorg, }} \mathrm{kcal} / \mathrm{mol}\right)\end{array}$ & $\begin{array}{c}\Delta G_{\text {solv }}-\Delta G_{\text {reorg. }} \\
(\mathrm{kcal} / \mathrm{mol})\end{array}$ \\
\hline$R=R_{1}=O C_{4} H_{9}$ & -1.7794 & 2.0902 & -3.8696 \\
\hline$R=R_{1}=\$-O C_{4} H_{9}$ & 0.9780 & 1.0572 & -0.0792 \\
\hline $\begin{array}{l}R=\bigcup-S_{4} H_{9} \\
R_{1}=S C_{4} H_{9} \\
\left(4\left(C_{4} S\right) \text { DTNi in Fig. } 11\right)\end{array}$ & 2.0040 & 0.9491 & 1.0550 \\
\hline $\begin{array}{c}R=R_{1}=S_{4} H_{9} \\
\left(2\left(C_{4} S\right) 2\left(C_{4} S P h\right) D T N i \text { in }\right. \\
\text { Fig 11.) }\end{array}$ & 3.9248 & 0.8942 & 3.0305 \\
\hline
\end{tabular}

Table 3: Comparison of calculated solubility values in cyclohexane between nickel dithiolenes containing alkoxy and alkylthio terminal groups.

The last two compounds shown in Table 3 possess the largest solvation energies in a model non-polar solvent and thus have the greatest potential as soluble dyes for the LCPDI. When the reorganization energy of the solute is taken into account, the results are similar. The molecular structures of these dyes are shown below in Fig. 11. 


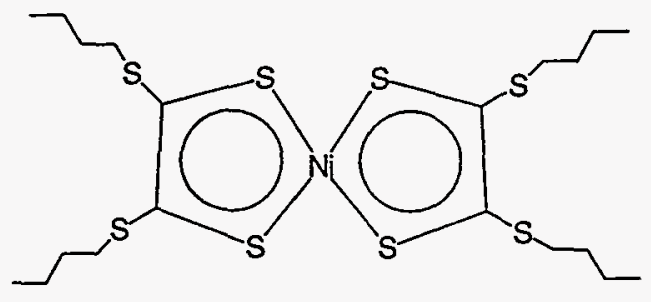

Tetrakis[(n-butylthio)bis(ethylene-1,2dithiolene]nickel

$4\left(\mathrm{C}_{4} \mathrm{~S}\right) \mathrm{DTNi}$

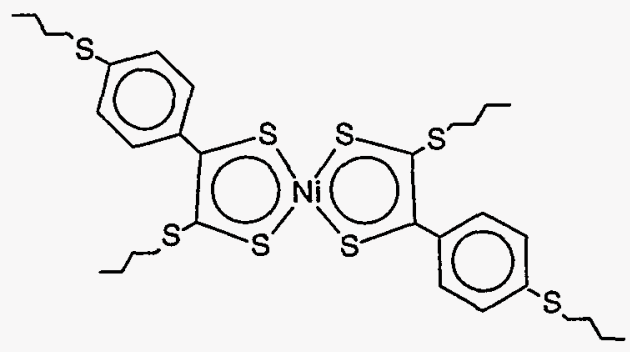

Bis[3-n-butylthio,4-(4-nbutylthiophenyl)ethylene1,2dithiolene]nickel

2( $\left.\mathrm{C}_{4} \mathrm{~S}\right) 2\left(\mathrm{C}_{4} \mathrm{SPh}\right)$ DTNi

Experimental $\lambda_{\text {max }}: 1002 \mathrm{~nm}^{4}$

Experimental $\lambda_{\text {max }}:$ Not yet known

Fig. 11: Molecular structures of the two most promising candidate dyes for the LCPDI device

After designing the $\mathbf{4}\left(\mathrm{C}_{4} \mathrm{~S}\right) \mathrm{DTNi}$ dye, it was found to have been previously synthesized in the literature, showing an optical absorption maximum at $1002 \mathrm{~nm}$ in benzene. ${ }^{4}$ If the near $\mathbb{R}$ absorption of this nickel complex follows the trend toward bathochromic shift shown in Fig. 10 for bisbuSDTNi when dissolved in a LC host, the absorption maximum should shift to very near the desired 1054-nm wavelength. The compound $2\left(C_{4} S\right) 2\left(C_{4} S P h\right) D T N i$ is new and has not yet been reported in the literature. This new dye may exhibit liquid crystalline properties based on its structural similarities to BisbuSDTNi (Fig. 9), which itself has a nematic liquid crystalline phase. Synthesis of these two new materials is curently in progress.

\section{6) Conclusion}

My work demonstrates that computational methods can provide very useful guidance in the development of nickel dithiolene dyes that fulfill the solubility and optical absorption requirements for a near-IR LCPDI device. My use of sulfur-containing terminal groups on the nickel dithiolene core shows great promise towards improving the solubility of these dyes in the LCPDI host as compared to their oxygen-containing analogs. LCPDI devices containing these new dyes will play an important role in the analysis and correction of wavefront aberrations on the OMEGA laser system, thus 
helping to advance the inertial confinement fusion program effort by improving the laser's ability to uniformly illuminate the target capsule.

My proposed new dye, $2\left(C_{4} S\right) 2\left(C_{4} S P h\right) D T N i$, has the potential to possess high solubility, strong near-IR absorption, and a liquid crystalline phase of its own. A material possessing these three features offers promise not only for use in LC electro-optical devices but also with other near-IR photonic device applications, including fiber optic and free-space communications. 


\section{7) References}

1. R. S. Craxton, R. L. McCrory and J. M. Soures, "Progress in Laser Fusion," Scientific American, 255, pp. 68-79, (1986).

2. C. R. Mercer and K. Creath, "Liquid Crystal Point Diffraction Interferometer for Wavefront Measurements," Applied Optics, 35 no. 10, pp. 1633-1642, (1996).

3. K. L. Marshall, Unpublished results, (1998).

4. W. Freyer, "Einfluß von Lösungsmitteln und Substituenten auf das Absorptionsverhalten von Nickel-dithiolenneutralchelaten," Z. Chem., 24. Jg. (1984) Heft 1 .

5. K. L. Marshall and S. D. Jacobs, "Near-Infrared Dichroism of a Mesogenic Transition Metal Complex and its Solubility in Nematic Hosts," Mol. Cryst. Liq. Cryst., 159, pp.181-186, (1988).

6. W. J. Herhe, Practical Strategies for Electronic Structure Calculations, Wavefunction, Inc., pp. 2-9, (1995).

7. J. J. P. Stewart, J. Comp. Aided Mol. Design, 4, 1(1990).

8. M. Cortrait, J. Gaultier, C. Polycarpe, A. M. Giroud and U. T. Mueller-Westerhoff, "Structure d'un Complexe de Métal de Transition Smectique," Acta Cryst., C39, pp. 833-835 (1983).

9. M. Colvin, "Continuum Models of Solvation," Lawrence Livermore National Laboratory, Online, Available <http://gutenberg.llnl.gov/ colvin/solvation/ solv.html >.

10. W. Huang, Wavefunction, Inc., personal communication (1998).

11. J. R. Wright, Jaguar User's Guide: Version 3.5, Schrödinger, Inc., (1998).

12. B. Honig, K. Sharp and A. Yang, "Macroscopic Models of Aqueous Solutions: Biological and Chemical Applications," J. Phys. Chem., 97, pp. 1101-1109, (1993).

13. W. T. Pollard, Schrödinger, Inc., personal communication (1998).

14. K. T. Schell and R. S. Porter, Mol. Cryst. Liq. Cryst., 188-1, pp. 97-103, (1990).

15. Dumur et al., Mol. Cryst. Liq Cryst., 45, pg. 127, 131, 139, (1978).

16. Tschlamler, Monatsh. Chem., 79, pp. 162-169, (1948). 
17. Boord et al., Ind. Eng. Chem., 41, pp. 609-615, (1949).

18. S. Corsello and I. Lippa, Unpublished results, (1998).

19. Z. S. Herman, R. F. Kirchner, G. H. Loew, U. T. Mueller-Westerhoff, A. Nazzal and M. C. Zerner, "Electronic Spectra and Structure of Bis(ethylene-1,2-dithiolato)nickel and Bis(propene-3-thione-1-thiolato)nickel," Inorg. Chem., 21, pp. 46-56, (1982).

20. U. T. Mueller-Westerhoff and B. Vance, "Dithiolenes and Related Species," Comprehensive Coordination Chemisty, 2, pp. 595-631, (1987).

21. W. P. Anderson, W. D. Edwards and M. C. Zerner, "Calculated Spectra of Hydrated Ions of the First Transition Metal Series," Inorg. Chem., 25 (16), pp. 2728-2732, (1986).

\section{Acknowledgments}

I would like to thank several scientists for their assistance. Kenneth L. Marshall, Research Engineer, Optical Materials was the supervising scientist for my project and helped me learn the chemistry of these dyes. Dr. Stephen Craxton, who was an advisor to me and the Director of the Summer Research Program, helped me learn about the inertial confinement fusion effort and the role of my project. Dr. Ansgar Schmidt helped me with the underlying theory behind the Poisson-Boltzmann equation. Finally, Dr. W. Thomas Pollard of Schrödinger, Inc. and Dr. Wayne Huang of Wavefunction, Inc. helped me to understand the limitations of their software packages and how to work around those limitations. 